\title{
The ever-expanding ERS fellowship programmes: achievements over the past 3 years
}

\author{
Maria G. Belvisi ${ }^{1}$, Rory E. Morty ${ }^{2}$, Gernot Rohde ${ }^{3}$, Marc Miravitlles ${ }^{4}$, \\ Kathryn A. Forrest ${ }^{5}$, Céline Genton ${ }^{5}$, Nathalie Ritter ${ }^{5}$, Nikoleta Luludi ${ }^{5}$, \\ Albert Jimenez ${ }^{6}$, David Rigau ${ }^{5,7}$, Thomy Tonia ${ }^{5,8}$, Valérie Vaccaro ${ }^{5}$, \\ Carine Pannetier ${ }^{5,6}$, Guy G. Brusselle ${ }^{9,10}$ and Stephen T. Holgate ${ }^{11}$
}

Affiliations: ${ }^{1}$ Respiratory Pharmacology Group, Airway Disease, National Heart and Lung Institute, Imperial College London, London, UK. ${ }^{2}$ Dept of Lung Development and Remodelling. Max Planck Institute for Heart and Lung Research, Bad Nauheim, Germany. ${ }^{3}$ Dept of Respiratory Medicine, Maastricht University Medical Center, Maastricht, The Netherlands. 'Pneumology Dept, Hospital Universitari Vall d'Hebron, Barcelona, Spain. ${ }^{5}$ Scientific Activities Dept, European Respiratory Society, Lausanne, Switzerland. ${ }^{6}$ Educational Activities Dept, European Respiratory Society, Lausanne, Switzerland. ${ }^{7}$ Iberoamerican Cochrane Centre - Biomedical Research Institute Sant Pau (IIB Sant Pau), Barcelona, Spain. ${ }^{8}$ Institute of Social and Preventive Medicine, University of Bern, Switzerland. ${ }^{9}$ Depts of Epidemiology and Respiratory Medicine, Erasmus Medical Center, Rotterdam, The Netherlands. ${ }^{10}$ Dept of Respiratory Medicine, Ghent University Hospital, Ghent, Belgium. ${ }^{11}$ Clinical and Experimental Sciences, Faculty of Medicine, University of Southampton, Southampton General Hospital, Southampton, UK.

Correspondence: Maria G. Belvisi, Respiratory Pharmacology Group, Airway Disease, National Heart and Lung Institute, Imperial College London, Sir Alexander Fleming Building, Exhibition Road, London, SW7 2AZ, UK.

E-mail: m.belvisidimperial.ac.uk

(y) @ERSpublications

The past 3 years have seen expansion of ERS fellowship programmes, driven by the 2013-2016 ERS fellowship strategy http://ow.ly/6r9D30279J7

The fellowship programmes are fundamental to the European Respiratory Society's (ERS) mission to promote lung health and drive standards for respiratory medicine globally. These programmes have been considerably expanded over the past 3 years and offer a wide range of training opportunities to boost early career scientists' competitiveness, enhance transnational mobility and promote scientific networks.

\section{Strategic development under the 2013-2016 fellowship plan}

Respiratory research remains significantly underfunded both at the European and the international level, as has been identified in the ERS Roadmap (www.ersroadmap.org). Over the past 3 years, fostering excellence in science to effectively address chronic lung disease and acute exacerbation has been one of the key priorities for the ERS Science Council, as reflected in its 2013-2016 fellowship strategy led by Maria Belvisi, ERS Research Director until September 2016 (from September 2016 onward, the ERS Research Director role has been re-focused and split into two different positions: the ERS Fellowships and Awards Director (hereafter referred to as the "ERS Fellowships Director") and the ERS Clinical Research Collaborations (CRC) Director; this takes into account the significant expansion in these two programmes). Within this framework, ERS fellowships have been significantly developed in terms of overall investment, number of fellowships awarded, diversity of opportunities and collaborations with key stakeholders.

Received: June 092016 | Accepted: June 142016

Conflict of interest: K.A. Forrest, C. Genton, N. Ritter, N. Luludi, A. Jimenez, D. Rigau, T. Tonia, V. Vaccaro and C. Pannetier are employees of the European Respiratory Society. Further disclosures can be found alongside this article at erj.ersjournals.com

Copyright @ERS 2016 
Since the last update on fellowships in the September 2013 issue of the European Respiratory Journal (ERJ) [1], new schemes have been launched, leading to an investment of about EUR 2000000 during the 2015-2016 financial year to train the next generation of respiratory scientists and clinicians. ERS members can now benefit from an even wider range of opportunities, depending on their background, area(s) of interest and career goals. Transnational mobility remains an essential aspect, with fellows undertaking their research or training in a (host) country, primarily in Europe, different from the (home) country where they are based. Fellowships are generally open to applicants of any nationality, whether they are researchers, clinicians or allied healthcare professionals, although some schemes have a specific geographical or thematic remit as shown in table 1.

\section{An ever-expanding fellowship portfolio}

Long-standing programmes such as the ERS long-term research fellowships (LTRF) and the ERS short-term research training fellowships (STRTF) remain key elements of the portfolio, and have been further diversified and expanded. The LTRF programme currently allows fellowship recipients to carry out research projects of 6-12 months duration at a host institution. From 2017, the scheme will be expanded to offer opportunities of up to 2 years. In contrast, the STRTF programme focuses, over a shorter timeframe (1-3 months duration), on transferring knowledge on specific research techniques that are not available in the researcher's home institute.

Interest in these two programmes has significantly grown since 2013, with an increase of up to $50 \%$ in the number of people applying. These fellowships also offer partnerships with a growing number of national respiratory societies in Europe and beyond, in line with ERS' increasing global dimension, as well as a dedicated scheme aimed at scientifically developing countries. New funding opportunities include a programme for paediatrics (the child lung health programme) developed to address a specific research gap.

The ERS Fellowships in Industry were introduced in 2015 and offer exciting new opportunities for medical doctors, young scientists and researchers to gain experience in the European respiratory pharmaceutical industry. Fellows bring their academic or hospital experience to pharmaceutical teams and are involved in research activities to enhance the management (diagnosis, prevention and treatment) of patients with respiratory diseases. Further industry-related schemes are in the pipeline for the future to meet the needs of early career researchers and address a specific demand for opportunities beyond the academic sector.

Looking forward, the upcoming RESPIRE3 fellowship programme, co-funded by the European Union (EU) through Horizon 2020, will be launched during autumn 2016. This flagship programme provides funding for post-doctoral researchers and represents a natural evolution following the RESPIRE1 (20092013) and ongoing RESPIRE2 (2013-2018) programmes, co-funded through the EU's Seventh Framework Programme (FP7). RESPIRE3 offers prestigious Marie Skłodowska-Curie fellowship opportunities at pre-selected host centres to scientists with the potential to become the future leaders in the respiratory field. It provides even more options and flexibility through 3-year global fellowships as well as 2-year European fellowships.

Two further thematic, stand-alone fellowships have also been launched recently to address specific, recognised needs. The clinical training fellowships, led by the ERS Education Council, offer healthcare professionals specific medical training opportunities, especially in terms of acquiring clinical skill(s) or learning procedure(s) that are not currently available at their home institution. These fellowships aim to improve daily practice as well as the diagnosis, treatment and follow-up of patients with respiratory diseases by disseminating clinical excellence.

A second dedicated scheme, the fellowship programme in guideline methodology, offers a unique opportunity to gain theoretical knowledge and practical experience in methodology for state of the art evidence-based guideline development, thereby contributing to knowledge transfer in Europe and internationally. This programme addresses an important need as the number of ERS Task Forces aiming to produce ERS guidelines and statements has grown considerably in recent years while the methodological requirements for guideline development have also increased.

\section{Peer-review structures reinforced to select the very best}

In line with ERS' strategic direction, the focus since 2013 has not only been to expand the quantity and diversity of the fellowship portfolio, but also to place stronger focus on quality and excellence. A competitive, open, equitable and transparent application and evaluation process has been put into place to select the very best applicants. During the 2013-2016 period, peer-review structures for research-based fellowships have been further enhanced with the introduction of an interview process for the LTRF and RESPIRE programmes, an expanded ERS College of Experts as well as the creation of the dedicated ERS Fellowships and Awards Working Group in 2014 comprised of established clinical and non-clinical researchers. In terms 


\section{Call deadlines and target group}

Short-term research training fellowships (STRTF)"

\section{ERS long-term research}

fellowships (LTRF)"

\section{ERS/EU RESPIRE fellowships} co-funded by the EU

\section{ERS fellowship in industry"}

\section{Fellowship programme in guideline} methodology

\section{ERS clinical training fellowships ${ }^{\S}$}

\section{1-3-month fellowships:}

Standard

International

ERS/EMBO fellowship jointly funded by ERS and EMBO (European Molecula Biology Organization

Walther Guerrero Ciquero tuberculosis fellowship

New since 2013:

Scientifically developing countries

ERS fellowship in memory of Dr Valia Kechagia

ERS/TTS fellowship jointly funded by ERS and TTS (Turkish Thoracic Society)

\section{6-24-month fellowships:}

Standard

International

ERS/EMBO fellowship jointly funded by ERS and EMBO

ERS/CTS (Canada) fellowship jointly funded by ERS, Canadian Lung

Association (CLA) and Canadian Thoracic Society (CTS)

ERS/SEPAR (Spain) fellowship jointly funded by ERS and SEPAR (Sociedad

Española de Neumología y Cirugía Torácical

New since 2013:

Scientifically developing countries

Child lung health

ERS/SPLF fellowship jointly funded by ERS and SPLF (Société de

Pneumologie

de Langue Française)

ERS/ALAT fellowship jointly funded by ERS and

ALAT (Asociación Latinoamericana de Tórax)

New RESPIRE3: programme to be launched during autumn 2016, offering European and Global

fellowships (2 to 3 years)

Please see the website for a full description

New programme aiming to provide fellowship recipients with experience of the pharmaceutical industry

Opportunities offered by industry

The programme is divided into two parts of 3-months duration each: training in systematic reviews in a specialised centre at Cochrane Iberoamerica (Spain) and training in guideline development at the UK National Institute for Health and Care Excellence (NICE)

Fellowship opportunities up to 6 months

The medical training should benefit the home institution when the successful applicant returns there
Two calls per year (deadlines: April 1 and October 1)

Target: MD, MSc/MRes, PhD, MD-PhD or equivalent

Target: MD, MSc/MRes, PhD, MD-PhD or equivalent lexcept for child lung health.

One call per year in 2017 and 2018 only (first call deadline on March 1, 2017)

Target: experienced researchers as per EU definition (PhD or equivalent of 4-years research experience) Please see the website for full eligibility criteria

Further information can be found on the ERS website about when new calls will be launched with potentially different target groups

Currently one call per year (deadline: July 1, 2016

Target: MD, MSc, PhD and MD-PhD as well as qualifie professionals either working in or with an interest in evidence-based medicine

Two calls per year (deadlines: February 1 and August 1 ) Target: qualified clinicians or healthcare professionals currently employed in respiratory medical practice

EU: European Union. " : since the ERS fellowship portfolio is expanding and dynamic, please refer to the ERS website for details of each scheme and up-to-date information (www.ersnet. org/fellowships). ๆ: Lead person: ERS Fellowships Director (ERS Science Council). + ${ }^{+}$Lead person: ERS Guidelines Director (ERS Science Council). ${ }^{\S}$ : Lead person: ERS Education Council Chair (ERS Education Council). 
of expertise, these two bodies include distinguished international experts covering the wider spectrum of respiratory medicine and science, as well as former ERS research fellowship recipients, as ERS believes that it is important to place past beneficiaries at the forefront of fellowship design and delivery. In addition, the Early Career Member Committee (ECMC) is represented as an equal contributor on the Fellowships and Awards Working Group.

\section{3-2016: key statistics and impact on respiratory research}

Under the expanded 2013-2016 fellowship programmes, 172 early career fellows representing the future of respiratory science and medicine have started their fellowships, to date, as illustrated in table 2 which provides an overview of the schemes since the previous ERJ editorial [1]. Since 2013, more than half of fellowships have been granted to top female scientists and clinicians, highlighting the overall gender balance. In terms of the nationality of fellows, over the past 3 years applicants from 47 nationalities have been selected. Around $70 \%$ of candidates were from Europe, notably from France, Germany, Greece, Italy, the Netherlands and Spain. The programme is also well-represented internationally with, for example, applications from Australia, Brazil, Canada, Egypt, India, Iran, Japan and Malaysia. This trend is expected to continue in the future as ERS grows into an increasingly global organisation.

Fellowship recipients are undertaking research in a range of diverse respiratory conditions (e.g. asthma, chronic obstructive pulmonary disease, lung cancer, cystic fibrosis and pulmonary hypertension), thereby helping to bridge a recognised funding gap, advancing the body of knowledge and establishing long-term collaborations. Out of the 20 host countries involved since 2013, Belgium, France, Germany, Spain, Switzerland and the UK remain among the most sought-after.

Just over one-third of the fellowships awarded during the period 2013-2016 were for basic science studies, notably through the 2-year RESPIRE2 programme; while a further quarter of all fellowships had a clinical focus (figure 1). Translational studies or research combining both basic and clinical elements accounted for a further one-third of all fellowships (figure 1). The diverse portfolio available attracts high-level applicants, with two-thirds of fellows holding a $\mathrm{PhD}$ or $\mathrm{MD}-\mathrm{PhD}$.

The fellowships granted since 2013 bring the overall total awarded to in excess of 620 investigators and clinicians funded since the programme was first launched in 1997. The developments seen during the 2013-2016 period reflect general trends over the past 20 years. For instance, during the period 1997-2016 more than half of the fellowships were awarded to women, while basic and clinical-related research accounted for one-third each of all fellowships.

\section{Focus on career development}

ERS fellowships continue to be highly valued in terms of career development and as a key-entry point into the Society, in large part due to the transnational mobility aspect, as revealed by a survey of fellows carried out in 2012 [1]. Notable alumni include Gernot Rohde, current ERS Education Council Chair and former long-term research fellow, and Agnes Boots, ERS ECMC Chair until September 2016 and current secretary of Group 03.03 as well as a past RESPIRE1 fellow.

TABLE 2 Overview of European Respiratory Society (ERS) fellowships awarded during the period 2013-2016 (as of May 2016)

\begin{tabular}{|c|c|c|c|}
\hline Fellowship 2013-2016 & Fellowships awarded ${ }^{+}$ & Nationality of fellows ${ }^{+}$ & Country of host institution ${ }^{+}$ \\
\hline $\begin{array}{l}\text { Short-term research training } \\
\text { fellowships (STRTF) }\end{array}$ & 76 (44 females) & Italy: $12.2 \%$ Greece: $11 \%$ & UK: $27.3 \%$ Germany: $16.3 \%$ \\
\hline RESPIRE2 ${ }^{\#}$ & 22 (8 females) & France, Germany, Spain: $5.2 \%$ each & Belgium: $6.4 \%$ \\
\hline Other" & 8 (2 females) & $\begin{array}{c}\text { Belgium, India: } 4.7 \% \text { each } \\
\text { Australia: } 4.1 \% \\
\text { Brazil, Canada, Japan: } 2.3 \% \text { each } \\
\text { Austria, Egypt, Iran, Ireland, Malaysia, } \\
\text { Portugal, Russia: } 1.7 \% \text { each } \\
\text { Other (28 nationalities): } 21.3 \%\end{array}$ & $\begin{array}{c}\text { Spain: } 5.8 \% \\
\text { Switzerland: } 5.2 \% \\
\text { Netherlands, Sweden, } \\
\text { USA: } 4.7 \% \text { each } \\
\text { Canada, Italy: } 2.9 \% \text { each } \\
\text { Denmark: } 1.7 \% \\
\text { Norway: } 1.2 \% \\
\text { Other (7 countries): } 4 \%\end{array}$ \\
\hline
\end{tabular}

\footnotetext{
\#: co-funded by the European Union; ${ }^{\text {I: }}$ fellowship in industry, programme in guideline methodology, or clinical training. ${ }^{+}$: in total 172
} fellowships were awarded (88 awarded to females). 
Figure 1 Overview of European Respiratory Society fellowships awarded during the period 20132016 (as of May 2016) according to type of research.

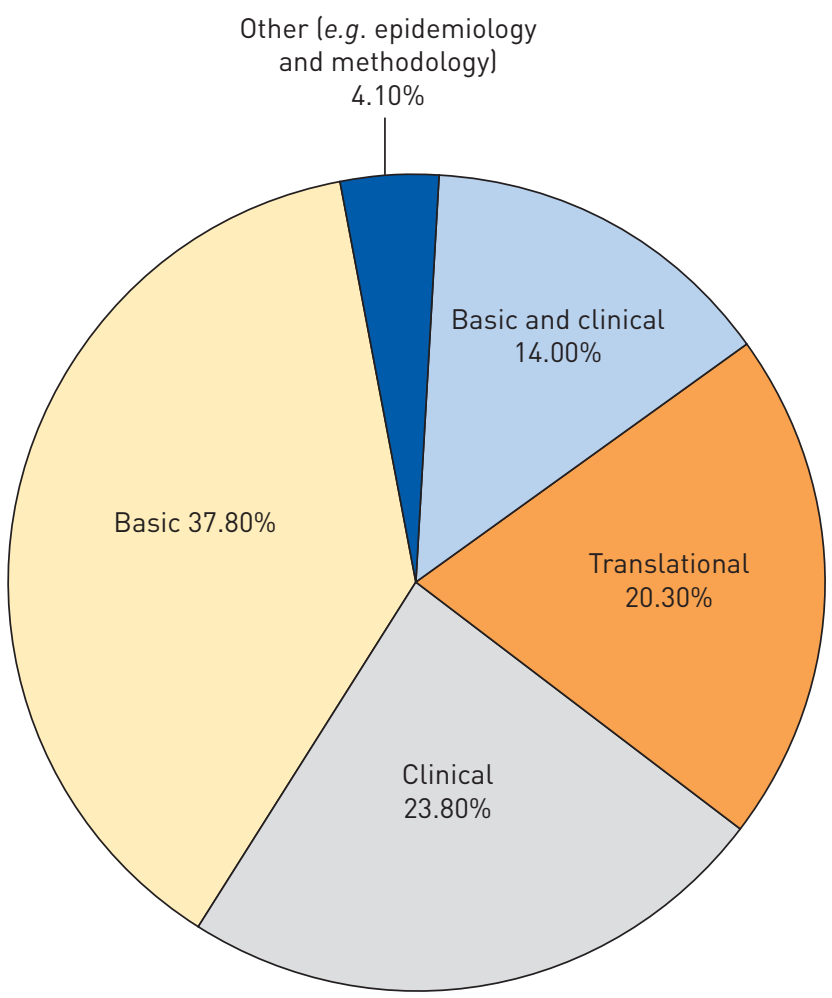

Recently, the career development element has been further reinforced through the launch of a pilot mentoring scheme to provide enhanced support to RESPIRE fellows, to be potentially extended in the future to other programmes. Fellowship recipients are also invited to join the ERS College of Experts as a mechanism to foster their post-fellowship engagement in the Society. Moreover, they are encouraged to actively participate in the wider activities of the ERS such as the ERS International Congress and its Career Development Fellowship and Young Scientist Networking evening events as well as the ERS Lung Science Conference and ERS Task Forces. Finally, cooperation with the ECMC has been further strengthened to ensure fellows are well-integrated within their Assemblies.

\section{Conclusions}

The ERS fellowships have been significantly expanded under the 2013-2016 fellowship strategy, with a more diverse and expanding portfolio thanks to increased ERS funding as well as capacity building through new schemes and partnerships. Structures and mechanisms to select the very best fellowship recipients and help them develop their career have also been strengthened, embedding excellence in respiratory science and research. 172 fellows have been funded since 2013, bringing the overall total to more than 620 since the fellowship programmes became operational in 1997, with an overall balanced distribution in terms of gender, geography and disciplines. These fellows represent the future of respiratory science and medicine and significantly contribute to ERS' mission while advancing science in their respective fields.

The future looks as promising and exciting for ERS members wishing to pursue a fellowship with the forthcoming RESPIRE3 and fellowship in industry programmes. The 2017-2019 fellowship strategy, to be led by the new ERS Fellowships Director, Rory Morty, will build on the major achievements of the past 3 years, ensuring the portfolio continues to address, both qualitatively and quantitatively, the needs of early career members.

\section{Acknowledgements}

ERS would like to thank all the organisations providing funding and support towards the ERS fellowship programmes, as presented in table 1. ERS would also like to thank members of the ERS Fellowships and Awards Working Group and of the ERS College of Experts.

\section{Reference}

1 Bals R, Ricou Yanmaz J, Schaffter C, et al. The European Respiratory Society fellowship programme: supporting young careers and building networks. Eur Respir J 2013; 42: 564-567. 